\title{
Hydrogen ion concentration and coronary artery bypass graft surgery with and without cardiopulmonary bypass
}

\author{
Cher Shiong Chuah ${ }^{1,2^{*}}$, Rachael Kirkbride ${ }^{1}$, R Peter Alston $^{2^{*}}$ and Joanne Irons ${ }^{3}$
}

\begin{abstract}
Background: Acidosis during cardiopulmonary bypass (CPB) has been related to the strong ion difference (SID) and the composition of intravascular fluids that are administered. Less intravascular fluids tend to be administered during off- than on-pump CABG and should influence the degree of acidosis that develops. This study aimed to explore the role of $\mathrm{CPB}$ in the development of acidosis by comparing changes in hydrogen ion concentration $\left(\left[\mathrm{H}^{+}\right]\right)$ and electrolytes in patients undergoing on- and off-pump coronary artery bypass graft (CABG) surgery.

Methods: Eighty two patients had arterial blood gas measurements pre-operatively, following CABG and at approximately $0600 \mathrm{~h}$ the morning after surgery. Carbon dioxide tension $\left(\mathrm{PaCO}_{2}\right)$ and concentrations of sodium, potassium, chloride, $\left[\mathrm{H}^{+}\right]$, bicarbonate and haemoglobin were measured and strong ion difference calculated. Data was analysed using mixed repeated-measures analysis of variance.

Results: Intra-operatively, mean SID decreased more in the on- compared to the off-pump group $(4.0 \mathrm{mmol} / \mathrm{L}, 95 \%$ confidence interval 2.8-5.3 mmol/L, p $<0.001$ ). Neither $\left[\mathrm{H}^{+}\right]$or $\mathrm{PaCO}_{2}$ changed significantly and there were no significant difference between the groups. By the morning following surgery, $\left[\mathrm{H}^{+}\right]$and $\mathrm{PaCO}_{2}$ had both increased $(p<0.001)$ and difference in SID had disappeared $(p=0.17)$.

Conclusion: Despite significant differences in changes in SID, there were no differences in $\left[\mathrm{H}^{+}\right]$between patients during or after CABG surgery whether performed on- or off-pump. This may be have been the result of greater haemodilution in the on- compared to the off-pump group, compensating for change in SID by reducing the concentration of weak acids. Although it was associated with significantly greater decrease in SID, CPB was not associated with any significant increased risk of acidosis.
\end{abstract}

Keywords: Cardiopulmonary bypass, Hydrogen ion concentration, Strong ion difference, Intravascular fluids, Coronary artery bypass grafting surgery

\section{Background}

Although originally performed without it, coronary artery bypass graft (CABG) surgery has traditionally been undertaken using cardiopulmonary bypass (CPB) since the 1970s. Since the 1990s there has been a resurgence of interest in performing CABG surgery off-pump that is without the use of $\mathrm{CPB}$ [1]. The motivation for undertaking CABG surgery off-pump was that avoiding $\mathrm{CPB}$

\footnotetext{
*Correspondence: chershiong@gmail.com; Peter.Alston@ed.ac.uk

${ }^{1}$ College of Medicine and Veterinary Medicine, University of Edinburgh, 47 Little France Crescent, Edinburgh EH16 4TJ, UK

${ }^{2}$ Department of Anaesthesia, Critical Care and Pain Medicine, Royal Infirmary of Edinburgh, 51 Little France Crescent, Edinburgh EH16 4SA, UK

Full list of author information is available at the end of the article
}

might reduce haemodynamic instability and the incidences of adverse events such as stroke and myocardial injury $[2,3]$. Another adverse event associated with $\mathrm{CPB}$ is the development of metabolic acidosis [4]. However, the aetiology of the metabolic acidosis remains unclear. Recent work has suggested that Stewart's quantitative acid-base approach might allows a better understanding of the causes of this acidosis [5,6].

Conventionally, lactate accumulation secondary to hypoperfusion was thought to be the prime driver of the metabolic acidosis. However, using Stewart's hypothesis, acidosis during $\mathrm{CPB}$ has been related to a decrease in strong ion difference (SID) during CPB [7]. The normal

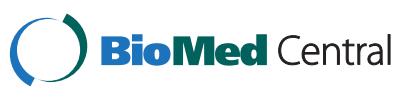


SID is $42 \mathrm{mmol} / \mathrm{L}$ [8]. Indeed, Hayhoe and colleagues demonstrated that the lactate concentration actually decreased during CPB [9]. Research indicates suggested that the solutions used to prime the $\mathrm{CPB}$ circuit influences metabolic acidosis $[7,9,10]$. Indeed, Himpe and colleagues found that metabolic acidosis could be limited by using priming solutions that have a high SID while Alston and colleagues demonstrated that changing the priming solution from Ringer's to Hartmann's which increases the SID of the prime from -2 to $27 \mathrm{mmol} / \mathrm{L}$, was associated with less metabolic acidosis $[4,11]$. In addition, the administration of intravascular fluids that alter SID also affect $\left[\mathrm{H}^{+}\right][12-14]$.

Off-pump CABG surgery avoids the intravascular infusion of large volumes of fluids used to prime the CPB circuit and so should reduce acidosis compared to on-pump CABG surgery. Indeed, it has been suggested that off-pump CABG surgery is associated with a lower incidence of metabolic acidosis [15]. Therefore, the aim of this study is to compare changes in electrolyte concentration and their influence of $[\mathrm{H}+]$ that occur in patients undergoing CABG surgery on- and off-pump.

\section{Methods}

Ethical approval by the South East Scotland Research Ethics Committee (11/WS/0110) and management approval $(2011 / R / C A R / 20)$ were granted for the study to be conducted at the Royal Infirmary of Edinburgh. Patient recruitment took place from January to May 2012. All patients scheduled to undergo isolated CABG surgery during this period were approached by researchers. Written consent was obtained from patients who wished to participate. Patients undergoing combined procedures and emergency surgery were exclusion criteria.

The study design was observational and patient allocation to on-or off-pump CABG surgery was at the discretion of the surgeon. Similarly, anaesthetic technique and the choice and volume of intravascular fluids that were administered were at the discretion of the anaesthesiologist. For patients on $\mathrm{CPB}$, the priming solution for the circuit was $1,800 \mathrm{ml}$ of Hartmann's, $200 \mathrm{ml}$ of mannitol 20\%, $50 \mathrm{ml}$ of sodium bicarbonate $8.4 \%$ and $10 \mathrm{ml}$ of heparin (10,000 iu). During $\mathrm{CPB}$, mean arterial pressure (MAP) was maintained between 60-80 mmHg. Hypotension was corrected with boluses of metaraminol $0.5 \mathrm{mg}$ if required.

As part of anaesthetic and post-operative care, routine arterial blood samples were obtained by operating department practitioners in theatre and by nurses in cardiac intensive treatment unit. Measurements were retrieved retrospectively from three routinely calibrated, RapidPoint 500 blood gas analysers (Siemens, Germany). Three blood gas measurements were made on each patient. A pre-operative measurement was taken after insertion of an arterial line before induction of anaesthesia. A measurement was performed immediately after CABG and the administration of protamine for heparin reversal. A third measurement was taken the morning after surgery at approximately 0600 hours. The blood samples were analysed for concentrations of sodium, potassium, chloride, hydrogen ion, bicarbonate, haemoglobin and partial pressure of carbon dioxide. SID and base excess (BE) were calculated using the formula in Appendices I and II [16]. Patient and surgical characteristics as well as all intravascular fluids administered during surgery were recorded.

Statistical analysis was carried out using SPSS v20 (Armonk, New York, USA). Differences in patient characteristics were explored using student's $t$-test. Differences in surgical characteristics were compared using Mann-Whitney $U$-test. Correlations between variables were explored using Pearson's correlation coefficient. Analysis of variance (ANOVA) was the main statistical test applied for the measurements to compare the difference between the on- and off-pump group as well as difference over the three time points. The probability of post-hoc tests were corrected for multiple testing using the Bonferroni correction and a p-value of less than $5 \%$ was considered significant.

A population sample size calculation was made to determine the number of patients required for each arm of the study. Previous research in this hospital showed that patients undergoing on-pump CABG surgery had a mean

Table 1 Characteristics of patients undergoing on- and off-pump CABG surgery

\begin{tabular}{|c|c|c|c|c|c|}
\hline & \multicolumn{2}{|c|}{ On-pump CABG surgery $(n=55)$} & \multicolumn{2}{|c|}{ Off-pump CABG surgery $(n=26)$} & \\
\hline & Mean & $95 \%$ Confidence interval & Mean & $95 \%$ Confidence interval & \\
\hline Age & 67.0 & $64.8-69.1$ & 63.4 & $59.8-66.9$ & $p=0.10$ \\
\hline Height (m) & 1.72 & $1.70-1.74$ & 1.71 & $1.67-1.75$ & $p=0.51$ \\
\hline Weight (kg) & 83.5 & $79.2-87.8$ & 87.3 & $81.3-93.3$ & $p=0.33$ \\
\hline BMI & 28.1 & 26.9-29.3 & 29.8 & $28.0-31.6$ & $p=0.21$ \\
\hline Gender & $\mathrm{n}$ & Percentage & $\mathbf{n}$ & Percentage & \\
\hline Male & 45 & $82 \%$ & 21 & $81 \%$ & \\
\hline Female & 10 & $18 \%$ & 5 & $19 \%$ & \\
\hline
\end{tabular}

Where BMI is body mass index. 
Table 2 Operative and recovery characteristics

\begin{tabular}{|c|c|c|c|c|c|}
\hline & \multicolumn{2}{|c|}{ On-pump CABG surgery $(n=55)$} & \multicolumn{2}{|c|}{ Off-pump CABG surgery $(n=26)$} & \\
\hline & Mean & 95\% Confidence interval & Mean & 95\% Confidence interval & \\
\hline Duration of surgery $(\mathrm{min})$ & 215 & $204-227$ & $186^{*}$ & 174-198 & $p<0.05$ \\
\hline Duration of CPB (min) & 103 & $94-111$ & - & - & \\
\hline \multirow[t]{2}{*}{ Total intravascular fluid volume (ml) } & 3570 & $3330-3811$ & $2190^{*}$ & $1816-2563$ & $p<0.001$ \\
\hline & Median & Interquartile range & Median & Interquartile range & \\
\hline Duration of tracheal intubation (h) & 15 & $8-20$ & $8^{*}$ & $6-12$ & $p<0.05$ \\
\hline Duration of critical care stay (h) & 47 & $23-86$ & $24^{*}$ & $20-48$ & $p<0.05$ \\
\hline
\end{tabular}

Where $C P B$ cardiopulmonary bypass and *:significant difference from on-pump group, $\mathrm{p}<0.05$ (Mann-Whitney U-test).

Table 3 Mean blood concentrations in on- and off-pump CABG surgery groups pre-operatively, following CABG and the morning following surgery

\begin{tabular}{|c|c|c|c|c|c|c|c|}
\hline & & \multicolumn{3}{|c|}{ On-pump $(n=55)$} & \multicolumn{3}{|c|}{ Off-pump ( $n=26)$} \\
\hline & & \multirow[t]{2}{*}{ Mean } & \multicolumn{2}{|c|}{ 95\% Confidence interval } & \multirow[t]{2}{*}{ Mean } & \multicolumn{2}{|c|}{ 95\% Confidence interval } \\
\hline & & & Lower & Upper & & Lower & Upper \\
\hline \multirow[t]{3}{*}{$\mathrm{Na}^{+}(\mathrm{mmol} / \mathrm{L})$} & Pre-operatively & 139.5 & 138.9 & 140.2 & 139.4 & 138.7 & 140.1 \\
\hline & Post-CABG & $135.8^{\ddagger}$ & 135.1 & 136.5 & $137.6^{\ddagger}$ & 136.7 & 138.5 \\
\hline & Next-morning & $137.2^{\ddagger}$ & 136.4 & 138.0 & $135.3^{\ddagger}$ & 134.5 & 136.1 \\
\hline \multirow[t]{3}{*}{$\mathrm{K}^{+}(\mathrm{mmol} / \mathrm{L})$} & Pre-operatively & 4.03 & 3.95 & 4.10 & 4.18 & 4.01 & 4.34 \\
\hline & Post-CABG & $4.81^{\ddagger}$ & 4.66 & 4.97 & $4.25^{\ddagger}$ & 4.06 & 4.44 \\
\hline & Next-morning & 4.70 & 4.59 & 4.80 & 4.66 & 4.48 & 4.84 \\
\hline \multirow[t]{3}{*}{$\mathrm{Cl}^{-}(\mathrm{mmol} / \mathrm{L})$} & Pre-operatively & 105.3 & 104.7 & 105.9 & 105.2 & 104.0 & 106.3 \\
\hline & Post-CABG & $111.0^{\ddagger}$ & 110.2 & 111.7 & $108.2^{\ddagger}$ & 106.9 & 109.5 \\
\hline & Next-morning & $106.8^{\ddagger}$ & 105.9 & 107.7 & $104.0^{\ddagger}$ & 102.7 & 105.3 \\
\hline \multirow[t]{3}{*}{$\mathrm{SID}(\mathrm{mEq} / \mathrm{L})$} & Pre-operatively & 38.2 & 37.5 & 38.9 & 38.4 & 37.3 & 39.6 \\
\hline & Post-CABG & $29.7^{\ddagger}$ & 29.0 & 30.3 & $33.7^{\ddagger}$ & 32.4 & 35.0 \\
\hline & Next-morning & 35.1 & 34.5 & 35.7 & 36.0 & 34.7 & 37.2 \\
\hline \multirow[t]{3}{*}[\mathrm{H}^{+}]{$(\mathrm{nmol} / \mathrm{L})$} & Pre-operatively & 38.1 & 37.4 & 38.8 & 39.0 & 37.1 & 40.9 \\
\hline & Post-CABG & 39.8 & 38.3 & 41.3 & 40.1 & 37.7 & 42.5 \\
\hline & Next-morning & 41.9 & 40.7 & 43.2 & 43.8 & 42.0 & 45.7 \\
\hline \multirow[t]{3}{*}{$\mathrm{HCO}_{3}^{-}(\mathrm{mmol} / \mathrm{L})$} & Pre-operatively & 24.9 & 24.2 & 25.5 & 24.6 & 23.7 & 25.5 \\
\hline & Post-CABG & 22.6 & 22.0 & 23.2 & 23.2 & 22.1 & 24.2 \\
\hline & Next-morning & 23.9 & 23.2 & 24.7 & 23.2 & 22.4 & 24.0 \\
\hline \multirow[t]{3}{*}{$\mathrm{PaCO}_{2}(\mathrm{kPA})$} & Pre-operatively & 5.23 & 5.07 & 5.39 & 5.30 & 5.05 & 5.56 \\
\hline & Post-CABG & 4.93 & 4.73 & 5.12 & 5.15 & 4.81 & 5.49 \\
\hline & Next-morning & 5.60 & 5.39 & 5.81 & 5.82 & 5.48 & 6.16 \\
\hline \multirow[t]{3}{*}{$\mathrm{Hb}(\mathrm{g} / \mathrm{L})$} & Pre-operatively & 13.8 & 13.5 & 14.1 & 14.4 & 13.6 & 15.1 \\
\hline & Post-CABG & $10.1^{\ddagger}$ & 9.7 & 10.5 & $12.1^{\ddagger}$ & 11.2 & 12.9 \\
\hline & Next-morning & $10.5^{\ddagger}$ & 10.1 & 10.8 & $12.0^{\ddagger}$ & 11.4 & 12.6 \\
\hline \multirow[t]{3}{*}{$B E(m E q / L)$} & Pre-operatively & 0.38 & -0.20 & 1.00 & 0.15 & -0.90 & 1.21 \\
\hline & Post-CABG & -1.96 & -2.66 & -1.26 & -1.25 & -2.41 & -0.09 \\
\hline & Next-morning & -0.75 & -1.38 & -0.13 & -1.17 & -2.13 & -0.22 \\
\hline
\end{tabular}

Where $\mathrm{Na}^{+}$sodium, $\mathrm{K}^{+}$potassium, $\mathrm{Cl}$ chloride, $\mathrm{SID}$ strong ion difference, $\left[\mathrm{H}^{+}\right]$hydrogen ion concentration, $\mathrm{HCO}_{3}^{-}$bicarbonate, $\mathrm{PaCO}{ }_{2}$ arterial carbon dioxide tension, $\mathrm{Hb}$ haemoglobin concentration, $C A B G$ coronary artery bypass grafting, next-morning: morning following surgery, ${ }^{\ddagger} \mathrm{p}<0.05$. 
$[\mathrm{H}+]$ of $36 \mathrm{nmol} / \mathrm{L}$ with a standard deviation of $6 \mathrm{nmol} / \mathrm{L}$ [4]. Based on this mean and standard deviation, it was initially calculated that 36 patients were needed in each group to detect an effect size of $4 \mathrm{nmol} / \mathrm{L}(\alpha=0.05$, power $=0.80)$ which was deemed to be a clinical important change in $[\mathrm{H}+]$. Due to the limited number of procedures performed, only 26 patients who underwent off-pump CABG surgery were recruited into the study. However, this shortfall in patients did not compromise the statistical power of the study. A retrospective power calculation based on the actual values obtained found that this study was able to detect a change of $4 \mathrm{nmol} / \mathrm{L}$ with a power of $0.84(\alpha=0.05)$.

\section{Results}

Eighty-two patients were approached: one patient declined to participate. Fifty five patients underwent on-pump CABG surgery and 26 patients in the off-pump CABG surgery. Patient characteristics are similar and there were no significant differences between the groups (Table 1). Operative characteristics differed between the groups. Off-pump patients had shorter durations of surgery and stay in the critical care areas and less intravascular fluids administered (Table 2).

\section{Hydrogen ion concentration, carbon dioxide tension and strong ion difference}

Mean concentrations of sodium, potassium, chloride, strong ion difference, hydrogen ion, bicarbonate, carbon dioxide tension, haemoglobin concentration are presented in Table 3.

Mixed repeated-measures ANOVA and post-hoc analysis applying the Bonferroni correction were used to analyse $\left[\mathrm{H}^{+}\right], \mathrm{PaCO}_{2}$ and SID. The results for these are shown and summarised in Figures 1,2 and 3. There were no detectable differences in $\left[\mathrm{H}^{+}\right](\mathrm{F}(1,79)=1.79, \mathrm{p}=0.185)$ and $\mathrm{PaCO}_{2}$ $(\mathrm{F}(1,79)=1.91, \mathrm{p}=0.171)$ between the groups. Both $\left[\mathrm{H}^{+}\right]$ and $\mathrm{PaCO}_{2}$ showed no significant change over the course of the operation. However, on the morning following surgery, $\left[\mathrm{H}^{+}\right]$was significantly higher than both pre-operative (mean difference $=4.3 \mathrm{nmol} / \mathrm{L}, \mathrm{p}<0.001$ ) and post-CABG $\left[\mathrm{H}^{+}\right]$(mean difference $=3.0 \mathrm{nmol} / \mathrm{L}, \mathrm{p}<0.001$ ). $\mathrm{PaCO}_{2}$ on the morning following surgery was also significantly higher than both pre-operative (mean difference $=0.45 \mathrm{kPa}$, $\mathrm{p}<0.001$ ) and post-CABG (mean difference $=0.68 \mathrm{kPa}$, $\mathrm{p}<0.001)$ time points.

There were significant differences in SID over time $(\mathrm{F}(2,158)=185.9, \mathrm{p}<0.001)$ as well as between groups

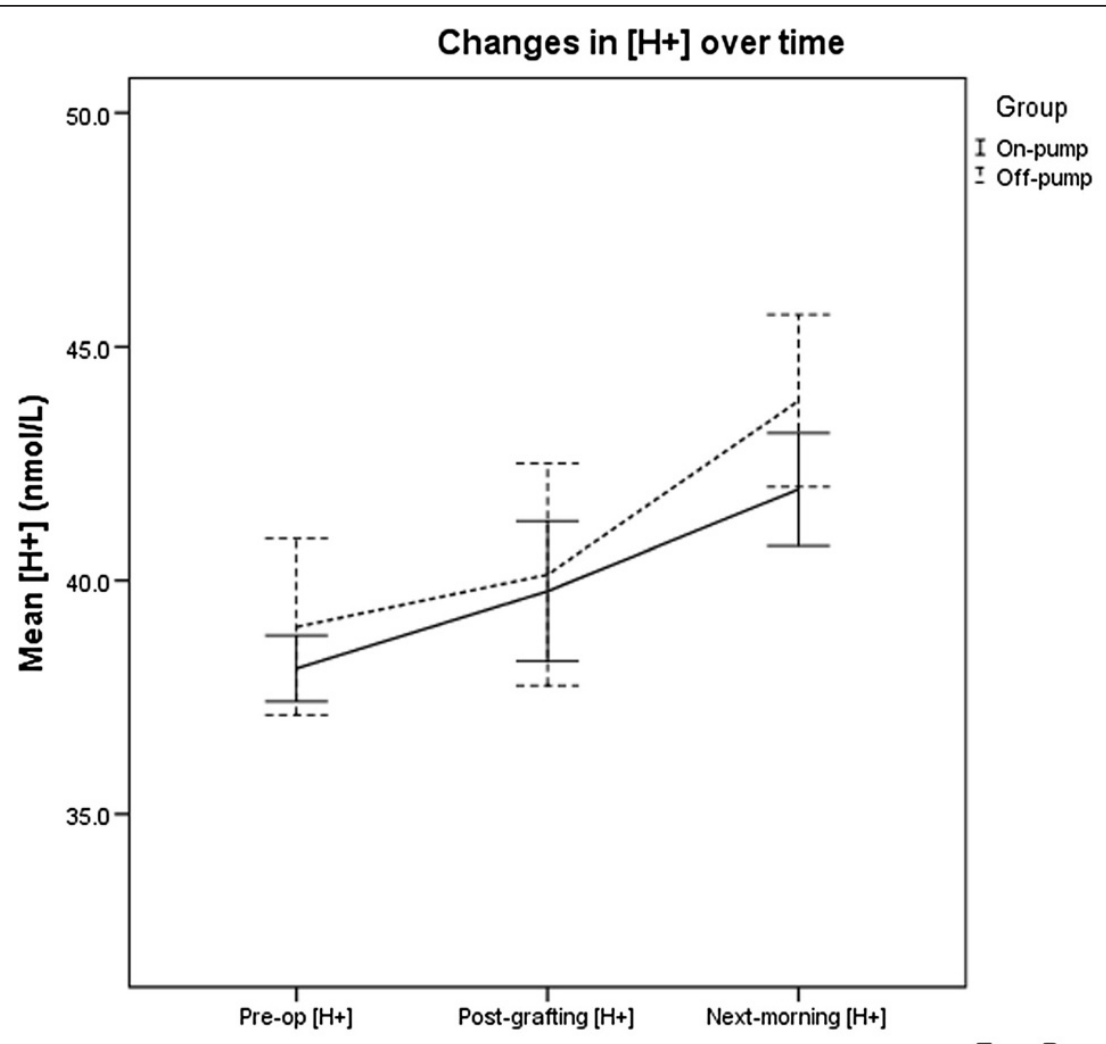

Error Bars: $95 \% \mathrm{Cl}$

Figure 1 Changes in hydrogen ion concentration in patients undergoing on- and off-pump coronary artery bypass grafting surgery. Mean hydrogen ion concentration $[\mathrm{H}+]$ and $95 \%$ confidence intervals for patients undergoing on- and off-pump patients over time. Where pre-op: pre-operatively, post-grafting: following coronary artery bypass grafting and next-morning: approximately 0600 on the morning following surgery. 


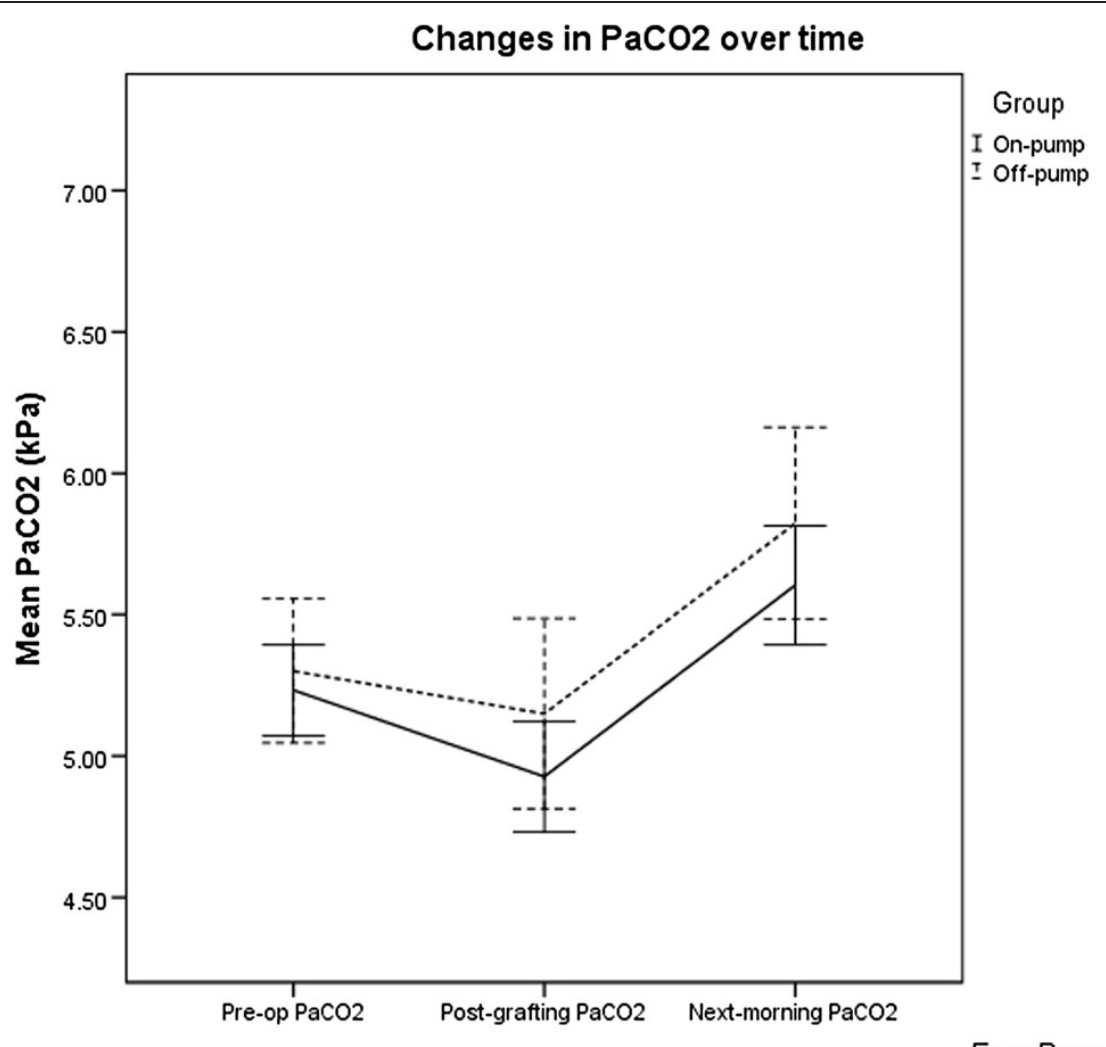

Error Bars: $95 \% \mathrm{Cl}$

Figure $\mathbf{2}$ Changes in arterial carbon dioxide tension in patients undergoing on- and off-pump coronary artery bypass grafting surgery. Mean arterial carbon dioxide tensions $\left(\mathrm{PaCO}_{2}\right)$ and $95 \%$ confidence intervals for patients undergoing on- and off-pump patients over time. Where pre-op: pre-operatively, post-grafting: following coronary artery bypass grafting and next-morning: approximately 0600 on the morning following surgery.

$(\mathrm{F}(1,79)=12.46, \mathrm{p}<0.001)$. Post-hoc analysis showed that mean SID differed significantly over all time points (Table 4). Over the course of surgery, both groups experienced a decrease in SID with on-pump patients experiencing a greater decrease than off-pump patients, resulting in a significant difference at the post-CABG measurement (mean difference $=4.0 \mathrm{mmol} / \mathrm{L}, 95 \% \mathrm{CI}$ 2.8-5.3 mmol/L, $\mathrm{p}<0.001)$. By the morning following surgery, the differences between on- and off-pump groups became non-significant and SID returned towards preoperative values (Figure 3).

\section{Intravascular fluids and tracheal extubation}

The compositions of fluids administered to both groups were similar (Figure 4). The mean total volumes of fluid administered intravascularly during surgery was $3,570 \mathrm{ml}$ (SD $739 \mathrm{ml}$ ) and 2,190 $\mathrm{ml}(\mathrm{SD} 877 \mathrm{ml}$ ) in the patients undergoing on- and off-pump groups respectively with a mean difference of 1,380 $\mathrm{ml}$ (95\% CI 970-1780 ml).

Patients whose tracheas were extubated before the measurement on the morning following surgery had a significantly higher mean $\mathrm{PaCO}_{2}$. Students $t$-test found that mean $\mathrm{PaCO}_{2}$ was $5.90 \mathrm{kPa}$ in patients who had undergone tracheal extubation and significantly $(\mathrm{p}<0.01)$ higher compared $5.40 \mathrm{kPa}$ in patients whose tracheas were still intubated. Tracheal extubation also correlated with an increase in $\mathrm{PaCO}_{2}$ (Pearson $\mathrm{r}=0.31, \mathrm{p}<0.01$ ).

\section{Predictors of hydrogen ion concentration}

Univariate correlations were performed comparing changes in $\left[\mathrm{H}^{+}\right]$and SID to changes in $\mathrm{PaCO}_{2}, \mathrm{Hb}$ and SID. $\left[\mathrm{H}^{+}\right]$ was found to be significantly correlated with $\mathrm{PaCO}_{2}$ $(\mathrm{r}=0.53, \mathrm{p}<0.01)$ and $\operatorname{SID}(\mathrm{r}=-0.35, \mathrm{p}<0.01)$. SID was significantly correlated with $\mathrm{Hb}(\mathrm{r}=0.48, \mathrm{p}<0.01)$. A multivariate linear regression model was then applied to assess the strength and independence of the relationships between the factors that correlated significantly with $\left[\mathrm{H}^{+}\right]$. A significant model was found using $\mathrm{PaCO}_{2}$ and SID as predictors of $\left[\mathrm{H}^{+}\right]$(adjusted $\mathrm{r}$ square $=0.48, \mathrm{~F}=33.0$, $\mathrm{p}<0.001$ ). The standardised coefficient $\beta$ for $\mathrm{PaCO}_{2}$ was 0.624 and SID was -0.473 (both $\mathrm{p}<0.001$ ). Haemoglobin, which was used as a marker of haemodilution, was not entered into the regression model as no significant univariate correlation was found between SID and $\mathrm{Hb}$. 


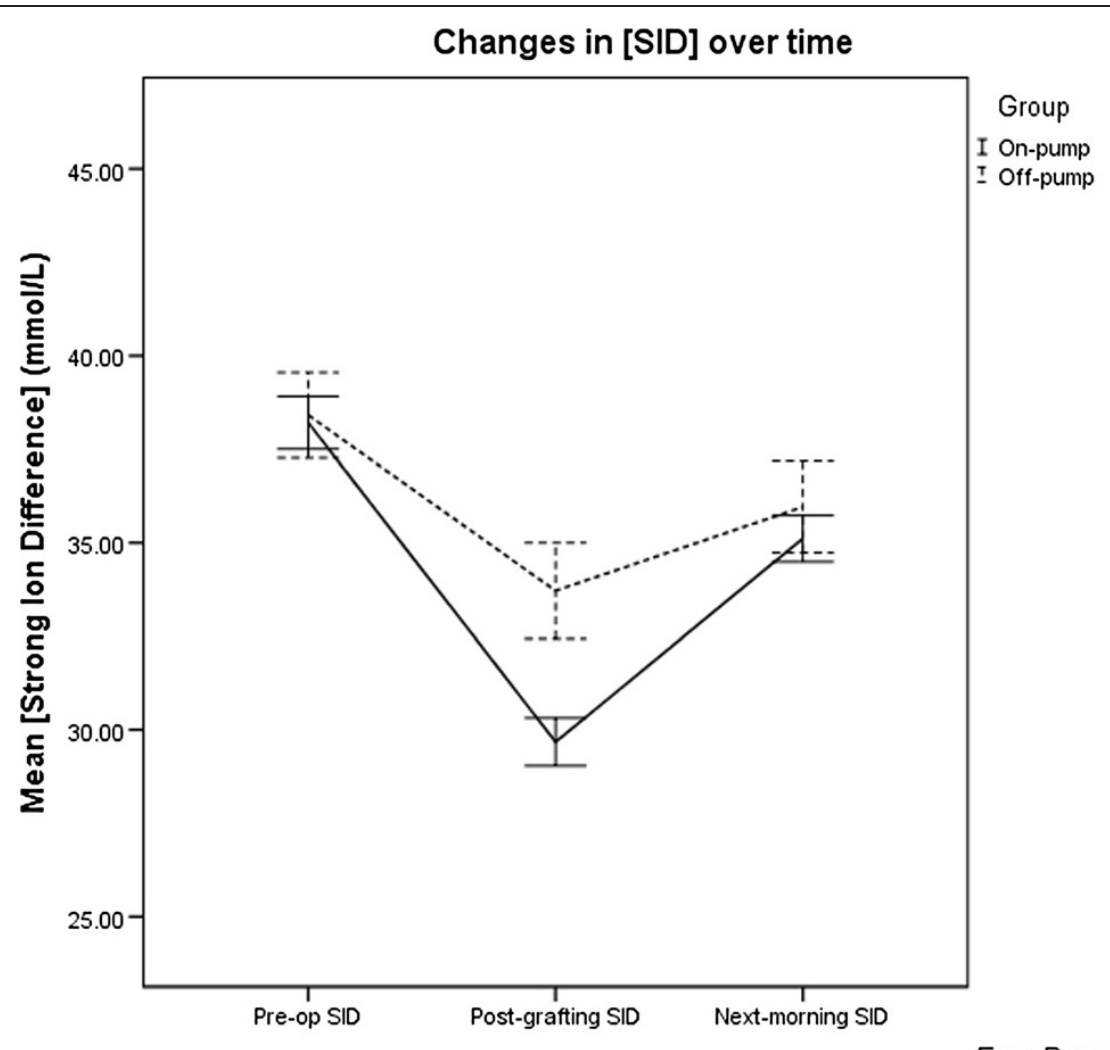

Error Bars: $95 \% \mathrm{Cl}$

Figure $\mathbf{3}$ Changes in strong ion difference in patients undergoing on- and off-pump coronary artery bypass grafting surgery. Mean concentrations of strong ion difference ([SID]) and 95\% confidence intervals for patients undergoing on- and off-pump patients over time. Where pre-op: pre-operatively, post-grafting: following coronary artery bypass grafting and next-morning: approximately 0600 on the morning following surgery.

\section{Discussion}

Intra-operative hydrogen ion concentration, carbon dioxide tension and strong ion difference

Over the course of surgery, there was a significant decrease in SID, with patients in the on-pump group demonstrating a greater decrease compared with the off-pump group. This was found to be related to the total volume of fluid administered intravascularly. According to Stewart's hypothesis, we would expect such a significant change in SID to directly affect $\left[\mathrm{H}^{+}\right]$or for a change in $\mathrm{PaCO}_{2}$ to neutralise the change in SID. However, $\left[\mathrm{H}^{+}\right]$and $\mathrm{PaCO}_{2}$ did not change over the course of surgery.

Therefore, an explanation for the lack of effect of SID on $\left[\mathrm{H}^{+}\right]$may be that the change in SID was compensated by changes in total weak acid concentration $\left(\mathrm{A}_{\mathrm{TOT}}\right) . \mathrm{A}_{\mathrm{TOT}}$ is mainly composed of albumin as the principal extracellular

Table 4 Changes in strong ion difference over time

\begin{tabular}{lll}
\hline Time points & Mean difference & $\mathbf{9 5 \%} \mathbf{C l}$ \\
\hline Pre-operatively to post-CABG & $6.62^{*}$ & $5.72-7.51$ \\
Post-CABG to morning following surgery & $3.84^{*}$ & $3.09-4.60$ \\
Pre-operatively to morning & $2.77^{*}$ & $1.90-3.65$ \\
following surgery & &
\end{tabular}

Where CABG is coronary artery bypass grafting, ${ }^{*} p<0.001$. weak acid [17]. During CPB, patients develop a dilutional hypoalbuminaemia as a result of intravascular fluid administration $[10,11,18]$. This hypoalbuminaemia induces a metabolic alkalosis, which counteracts the acidosis induced by the administration of intravascular fluids $[7,10]$.

To support this explanation, this study used haemoglobin concentration as a marker of haemodilution as any dilution of albumin and other blood proteins can be indirectly inferred from changes in haemoglobin [7]. Indeed, SID was found to correlate with haemoglobin which suggests that a decrease in SID is accompanied with a corresponding haemodilution. Hence, a possible explanation for why the difference in SID between the groups did not affect $\left[\mathrm{H}^{+}\right]$is the more fluid that is administered, the more SID decreases and at the same time, $\mathrm{A}_{\mathrm{TO}}$ is diluted. Therefore the acidifying effects of a decrease in SID may be balanced by the alkalizing effects of a dilution in $\mathrm{A}_{\text {TOT. }}$. In hindsight, measuring lactate might have improved the interpretation of the results.

\section{Post-operative changes in hydrogen ion concentration}

Post-operatively, $\left[\mathrm{H}^{+}\right]$and $\mathrm{PaCO}_{2}$ significantly increased in both groups and there were no significant differences between them. In addition, changes in SID tended to 


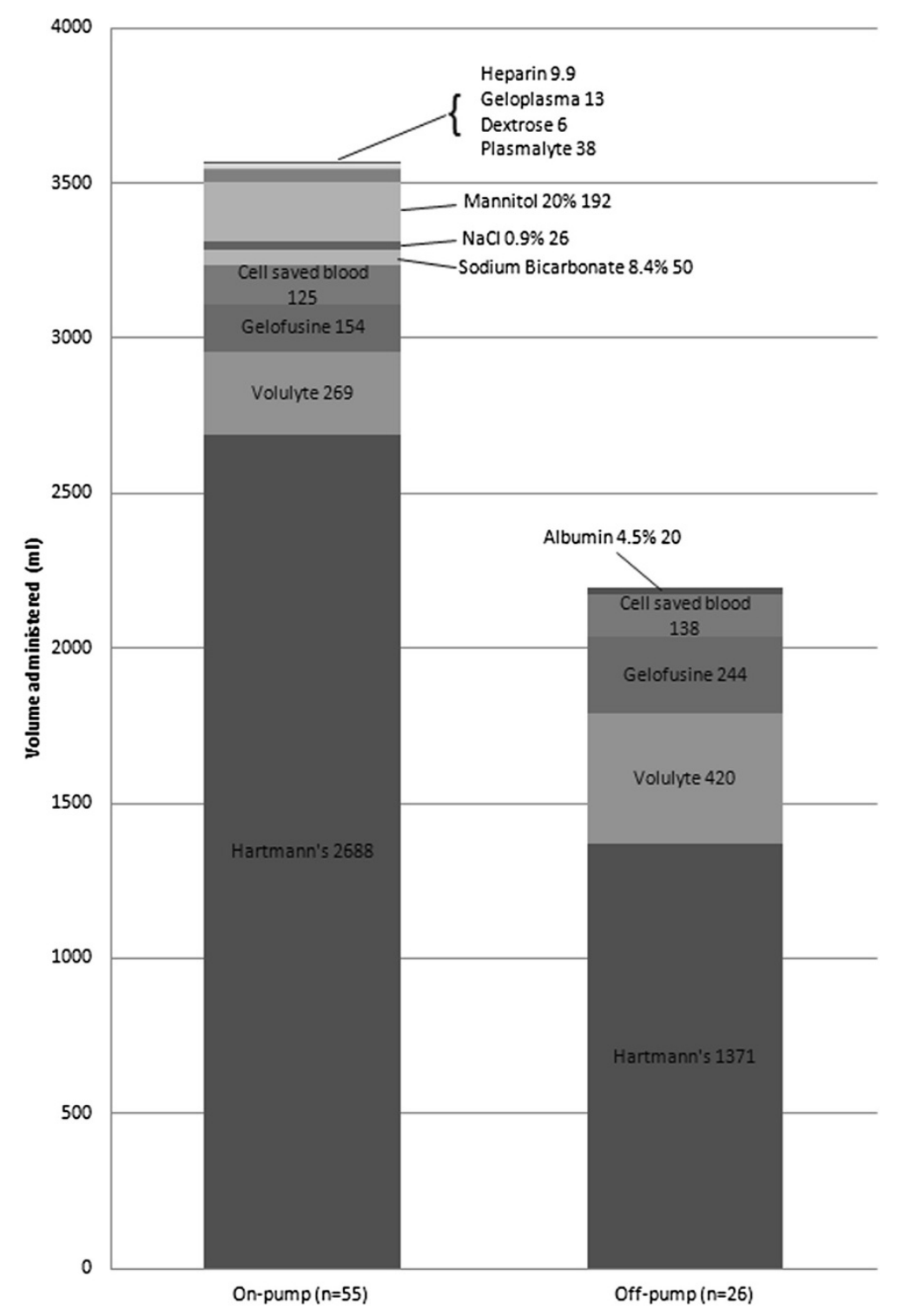

Figure 4 Average composition of fluids given to patients undergoing on-pump and off-pump coronary artery bypass graft surgery.

resolve towards the baseline measurement and the difference in SID between on- and off-pump groups disappeared. Together these findings suggest that the majority of the change in $\left[\mathrm{H}^{+}\right]$post-operatively can be attributed to changes in $\mathrm{PaCO}_{2}$.

\section{On- compared to off-pump CABG surgery}

This study demonstrates that patients undergoing off-pump surgery received less intravascular fluids and therefore, experience less severe disturbances of sodium, potassium, chloride, bicarbonate and so SID in the immediate post-CABG period compared to on-pump patients. However, these differences tend to narrow or disappear by the morning following surgery which is between 12-18 hours postoperatively.

\section{Implications}

The findings of this study confirm that changes in SID are related to intravascular fluids that are administered. The findings cannot preclude the possibility that an acidosis develops by the end of surgery. However, following completion of CABG and protamine administration, there is no significant change in $\left[\mathrm{H}^{+}\right]$from baseline or between on- and off-pump groups, despite significant differences in SID. Ultimately, the changes in SID resolved relatively quickly, such that by the morning following SID is almost back to its baseline measurement. Therefore, two things can be inferred: firstly, while fluids affect SID, this may not necessarily lead on to acidosis and secondly, the use of cardiopulmonary bypass seems to have little impact on the development of acidosis. 


\section{Conclusion}

This study found that there were no significant differences in $\left[\mathrm{H}^{+}\right]$between patients undergoing on- or off-pump CABG surgery. The use of CPB is associated with more intravascular fluids and leads to a greater decrease in SID. However, this does not impact acidosis. SID normalised post-operatively and the difference between groups at the end of CPB diminished by the morning following surgery.

\section{Appendix}

\section{Appendix I}

Formula for calculating strong ion difference:

$$
S I D=\left[\mathrm{Na}^{+}\right]+\left[\mathrm{K}^{+}\right]-\left[\mathrm{Cl}^{-}\right]
$$

\section{Appendix II}

Formula for calculating base excess:

$$
\begin{aligned}
\text { B.E. }= & 0.02786 \times \mathrm{PaCO}_{2}(\mathrm{mmHg}) \times 10^{(p H-6.1)} \\
& +13.77 \times p \mathrm{H}-124.58
\end{aligned}
$$

\begin{abstract}
Abbreviations
CPB: Cardiopulmonary bypass; CABG: Coronary artery bypass grafting: SID: Strong ion difference; BE: Base excess; ANOVA: Analysis of variance; $\left[\mathrm{H}^{+}\right]$: Hydrogen ion concentration; $\mathrm{PaCO}_{2}$ : Arterial carbon dioxide tension;

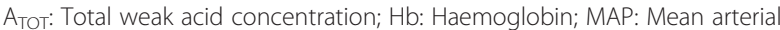
pressure
\end{abstract}

\section{Competing interests}

The authors declare that they have no competing interests.

\section{Authors' contributions}

CSC carried out patient recruitment, data collection, performed the statistical analyses and drafted the manuscript. RK carried out patient recruitment, data collection, reviewed the statistics and the draft manuscript. RPA conceived of the study, supervised its implementation, provided statistical guidance and reviewed the manuscript. JI assisted in patient recruitment, provided advice and reviewed the statistics and the manuscript. All authors read and approved the final manuscript.

\section{Acknowledgements}

This study was undertaken as part of a Year Four Student Selected Component at the College of Medicine and Veterinary Medicine at the University of Edinburgh. We are grateful to Dr Margaret MacDougall for her statistical advice.

\section{Author details}

${ }^{1}$ College of Medicine and Veterinary Medicine, University of Edinburgh, 47 Little France Crescent, Edinburgh EH16 4TJ, UK. ²Department of Anaesthesia, Critical Care and Pain Medicine, Royal Infirmary of Edinburgh, 51 Little France Crescent, Edinburgh EH16 4SA, UK. 3 Department of Anaesthesia, Papworth Hospital, Papworth Everard, Cambridge CB23 3RE, UK.

Received: 18 May 2013 Accepted: 15 August 2013

Published: 20 August 2013

\section{References}

1. Jansen EW, Borst C, Lahpor JR, Gründeman PF, Eefting FD, Nierich A, et al: Coronary artery bypass grafting without cardiopulmonary bypass using the octopus method: results in the first one hundred patients. J Thorac Cardiovasc Surg 1998, 116(1):60-67.

2. Shroyer AL, Grover FL, Hattler B, Collins JF, McDonald GO, Kozora E, et al: On-pump versus off-pump coronary-artery bypass surgery. N Engl J Med 2009, 361(19):1827-1837.
3. Puskas JD, Williams WH, Duke PG, Staples JR, Glas KE, Marshall JJ, et al: Off-pump coronary artery bypass grafting provides complete revascularization with reduced myocardial injury, transfusion requirements, and length of stay: a prospective randomized comparison of two hundred unselected patients undergoing off-pump versus conventional coronary artery bypass grafting. J Thorac Cardiovasc Surg 2003, 125(4):797-808.

4. Alston RP, Theodosiou C, Sanger K: Changing the priming solution from Ringer's to Hartmann's solution is associated with less metabolic acidosis during cardiopulmonary bypass. Perfusion 2007, 22(6):385-389.

5. Prough DS, White R: Acidosis associated with perioperative saline administration: dilution or delusion? Anesthesiol 2000, 93(5):1167-1169.

6. Stewart PA: Modern quantitative acid-base chemistry. Can J Physiol Pharmacol 1983, 61(12):1444-1461.

7. Alston RP, Cormack L, Collinson C: Metabolic acidosis developing during cardiopulmonary bypass is related to a decrease in strong ion difference. Perfusion 2004, 19(3):145-152.

8. Gattinoni L, Carlesso E, Cadringher P, Caironi P: Strong ion difference in urine: new perspectives in acid-base assessment. Crit Care 2006, 10(2):137.

9. Hayhoe M, Bellomo R, Liu G, McNicol L, Buxton B: The aetiology and pathogenesis of cardiopulmonary bypass-associated metabolic acidosis using polygeline pump prime. Intensive Care Med 1999, 25(7):680-685.

10. Liskaser FJ, Bellomo R, Hayhoe M, Story D, Poustie S, Smith B, et al: Role of pump prime in the etiology and pathogenesis of cardiopulmonary bypass-associated acidosis. Anesthesiol 2000, 93(5):1170-1173.

11. Himpe D, Neels H, De Hert S, Van Cauwelaert P: Adding lactate to the prime solution during hypothermic cardiopulmonary bypass: a quantitative acid-base analysis. Br J Anaesth 2003, 90(4):440-445.

12. Scheingraber $S$, Rehm M, Sehmisch C, Finsterer U: Rapid saline infusion produces hyperchloremic acidosis in patients undergoing gynecologic surgery. Anesthesiol 1999, 90(5):1265-1270.

13. Waters $\mathrm{JH}$, Miller LR, Clack S, Kim JV: Cause of metabolic acidosis in prolonged surgery. Crit Care Med 1999, 27(10):2142-2146.

14. Rahn $\mathrm{H}$ : Body temperature and acid-base regulation (review article). Lung 1974, 151(2):87-94.

15. Lancey RA, Soller BR, Vander Salm TJ: Off-pump versus on-pump coronary artery bypass surgery: a case-matched comparison of clinical outcomes and costs. Heart Surg Forum 2000, 3(4):277-281.

16. Calculated bicarbonate $\&$ base excess. http://www-users.med.cornell.edu/ spon/ picu/calc/basecalchtm.

17. Figge J, Mydosh T, Fencl V: Serum proteins and acid-base equilibria: a follow-up. J Lab Clin Med 1992, 120(5):713-719.

18. Hatherill M, Salie S, Waggie Z, Lawrenson J, Hewitson J, Reynolds L, et al: Hyperchloraemic metabolic acidosis following open cardiac surgery. Arch Dis Child 2005, 90(12):1288-1292.

doi:10.1186/1749-8090-8-184

Cite this article as: Chuah et al:: Hydrogen ion concentration and coronary artery bypass graft surgery with and without cardiopulmonary bypass. Journal of Cardiothoracic Surgery 2013 8:184

\section{Submit your next manuscript to BioMed Central and take full advantage of:}

- Convenient online submission

- Thorough peer review

- No space constraints or color figure charges

- Immediate publication on acceptance

- Inclusion in PubMed, CAS, Scopus and Google Scholar

- Research which is freely available for redistribution 